\title{
RADIOCARBON TO CALENDAR DATE CONVERSION: CALENDRICAL BAND WIDTHS AS A FUNCTION OF RADIOCARBON PRECISION
}

\author{
F. G. McCORMAC and M. G. L. BAILLIE
}

The Queen's University of Belfast, School of Geosciences, Palaeoecology Centre Belfast BT7 1NN, Northern Ireland

\begin{abstract}
Accurate high-precision ${ }^{14} \mathrm{C}$ dating (i.e., $\pm 20 \mathrm{yr}$ precision or less on the ${ }^{14} \mathrm{C}$ date) provides the narrowest calendrical band width and, hence, the best age range determination possible. However, because of the structure in the ${ }^{14} \mathrm{C}$ calibration curve, the calendar age range for a given ${ }^{14} \mathrm{C}$ precision is not constant throughout the calibration range. In this study, we quantify the calendar band widths for a range of ${ }^{14} \mathrm{C}$ precisions throughout the calibration range. We show that an estimate of the likely calendar band width in years can be obtained from the expression: Band width $(\mathrm{yr})=2.12 \times{ }^{14} \mathrm{C}$ precision $(1$ o $)+54.6$. We also show that calendar band widths are widest around $4000 \mathrm{BP}$ at the start of the Bronze Age, and become narrow through the later Bronze Age and Iron Age and back into the Neolithic.
\end{abstract}

\section{INTRODUCTION}

${ }^{14} \mathrm{C}$ dates are reported as BP values with an associated precision (Stuiver \& Polach 1977). Typically, the quoted error represents \pm one standard deviation $(1 \sigma)$, as determined by the total number of accumulated counts for that sample. Most laboratories also include an error multiplier that reflects the uncertainty associated with repeated dating of identical sample material. The ${ }^{14} \mathrm{C}$ date and total associated error are then converted to a calendar date (Stuiver 1989), using the internationally agreed ${ }^{14} \mathrm{C}$ calibration curve determined by Stuiver and Pearson (1986) and Pearson and Stuiver (1986) using a computer program developed by Stuiver and Reimer (1986). Probabilistic calibration techniques have also been developed by van der Plicht and Mook (1989) and Stuiver and Reimer (1987). Calibration introduces two additional sources of uncertainty in the final calendar date. First, because the calibration curve, itself, is a set of ${ }^{14} \mathrm{C}$ measurements made at decadal/bidecadal resolution on dendrochronologically dated wood, each point on the curve has an associated ${ }^{14} \mathrm{C}$ error and error multiplier. Second, because the curve is not smooth, but contains considerable structure, the calendrical band width for a ${ }^{14} \mathrm{C}$ date of a given precision varies at different points on the calibration curve.

Stuiver and Pearson (1986), Pearson and Stuiver (1986) and Stuiver and Becker (1986) published high-precision ${ }^{14} \mathrm{C}$ calibration data in the Calibration Issue of RADIOCARBON (Stuiver \& Kra 1986). In their papers, they included tables of calibrated age ranges, for a set of ${ }^{14} \mathrm{C}$ precisions, at dates in the 80-4020 BP range in bidecadal intervals. These tables provide a useful guide to the calendar band width that can be expected for a ${ }^{14} \mathrm{C}$ date of a given precision, but are restricted in range (80-4020 BP), and do not readily inform the user of the variations in band width as a function of ${ }^{14} \mathrm{C}$ age. Here, we quantify the calendar age ranges for a set of ${ }^{14} \mathrm{C}$ precisions at all ${ }^{14} \mathrm{C}$ dates within the calibration range. This will be of use to archaeologists, who should be able to obtain an estimate of laboratory ${ }^{14} \mathrm{C}$ precision based on sample size and expected age, and thereby determine whether or not the probable calendrical band width is useful. We also show that calibration band widths are greatest for all precisions around $4000 \mathrm{BP}$, at the start of the Bronze Age, and decrease through the later Bronze Age and Iron Age and into the Neolithic. This is attributed to the greatest rate of change of $\Delta^{14} \mathrm{C}$ being near $4000 \mathrm{BP}$. 


\section{METHOD}

Stuiver and Reimer (1986) compiled a data set, ATM20, for use in their calibration computer program. This file consists of calendar dates derived by dendrochronology and the associated ${ }^{14} \mathrm{C}$ dates and errors at decadal/bidecadal intervals. In this study, we used ATM20 to determine the calendrical band widths of ${ }^{14} \mathrm{C}$ dates at a series of precisions. The method involved fitting a cubic spline curve to the data set and interpolating at intervals of one year. Figure 1 shows the cubic spline interpolation superimposed on a linear interpolation (Stuiver \& Reimer 1986) of a section of the original data. Checks at a range of ${ }^{14} \mathrm{C}$ dates showed that both techniques yielded calendrical band widths that were within a few years of each other. We chose the spline because we agree with Suess and Linick (1990) that unknown parts of a function in nature can best be approximated by a spline. Having obtained the spline we then stepped through ${ }^{14} \mathrm{C}$ age (1 step every $5{ }^{14} \mathrm{C} \mathrm{yr}$ ) from 8100-150 BP, and recorded the calendar ages at the intercepts of the values

$$
\pm\left(\left({ }^{14} \mathrm{C} \text { precision }\right)^{2}+(\text { calibration curve } \sigma)^{2}\right)^{3 / 2}
$$

with the calibration curve. The difference between the calendar ages at the intercepts gives the calendrical band width for a given ${ }^{14} \mathrm{C}$ date and associated precision. The band widths, as a function of ${ }^{14} \mathrm{C}$ age (BP), were plotted for four ${ }^{14} \mathrm{C}$ precisions in Figure $2(\mathrm{~A}-\mathrm{D})$.

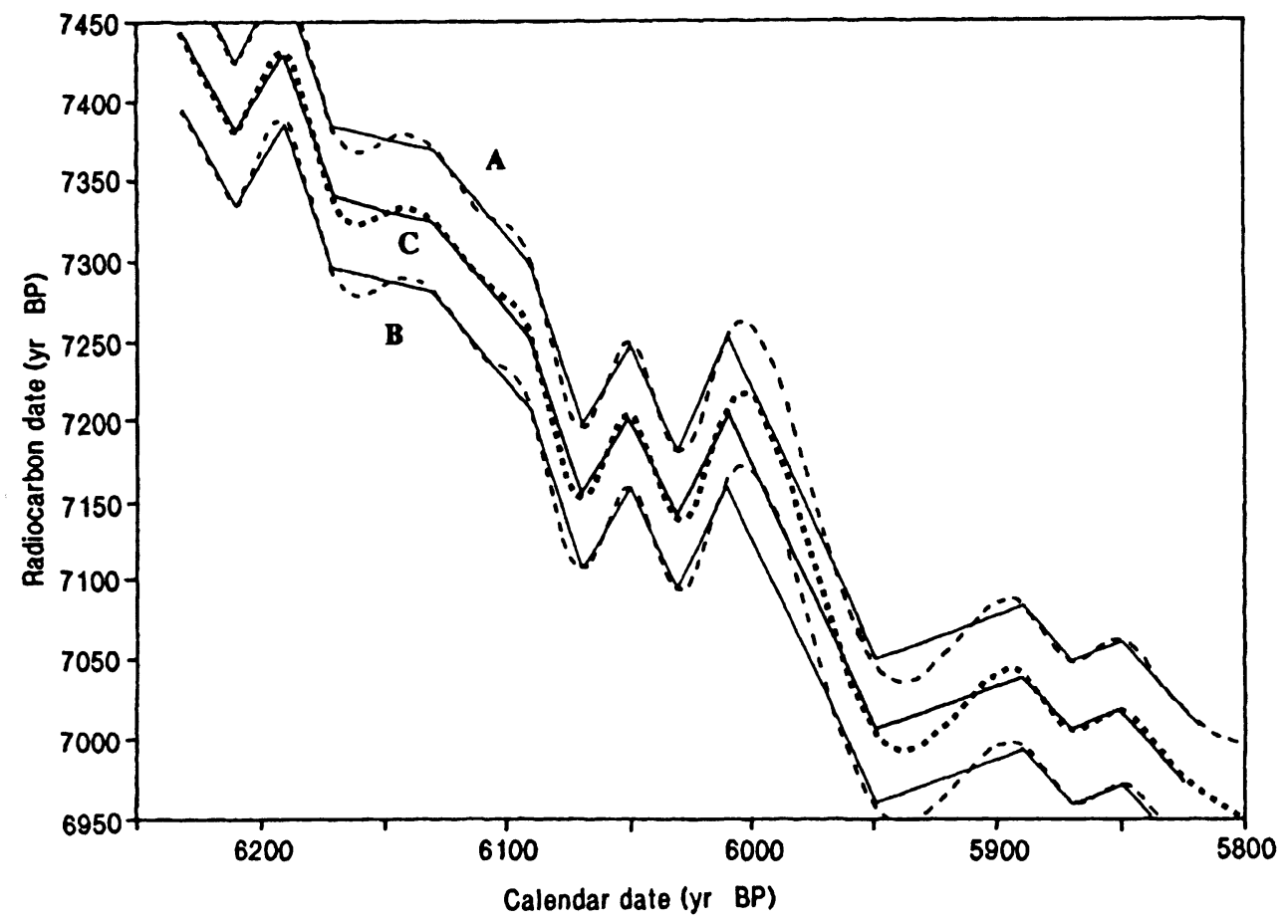

Fig. 1. Section of the ${ }^{14} \mathrm{C}$ calibration curve. $-=$ linear interpolations between data points,.....$=$ cubic spline interpolations; $\mathrm{C}=$ interpolated measurements; $\mathrm{A}$ and $\mathrm{B}= \pm 1 \sigma$ errors on the measurements 


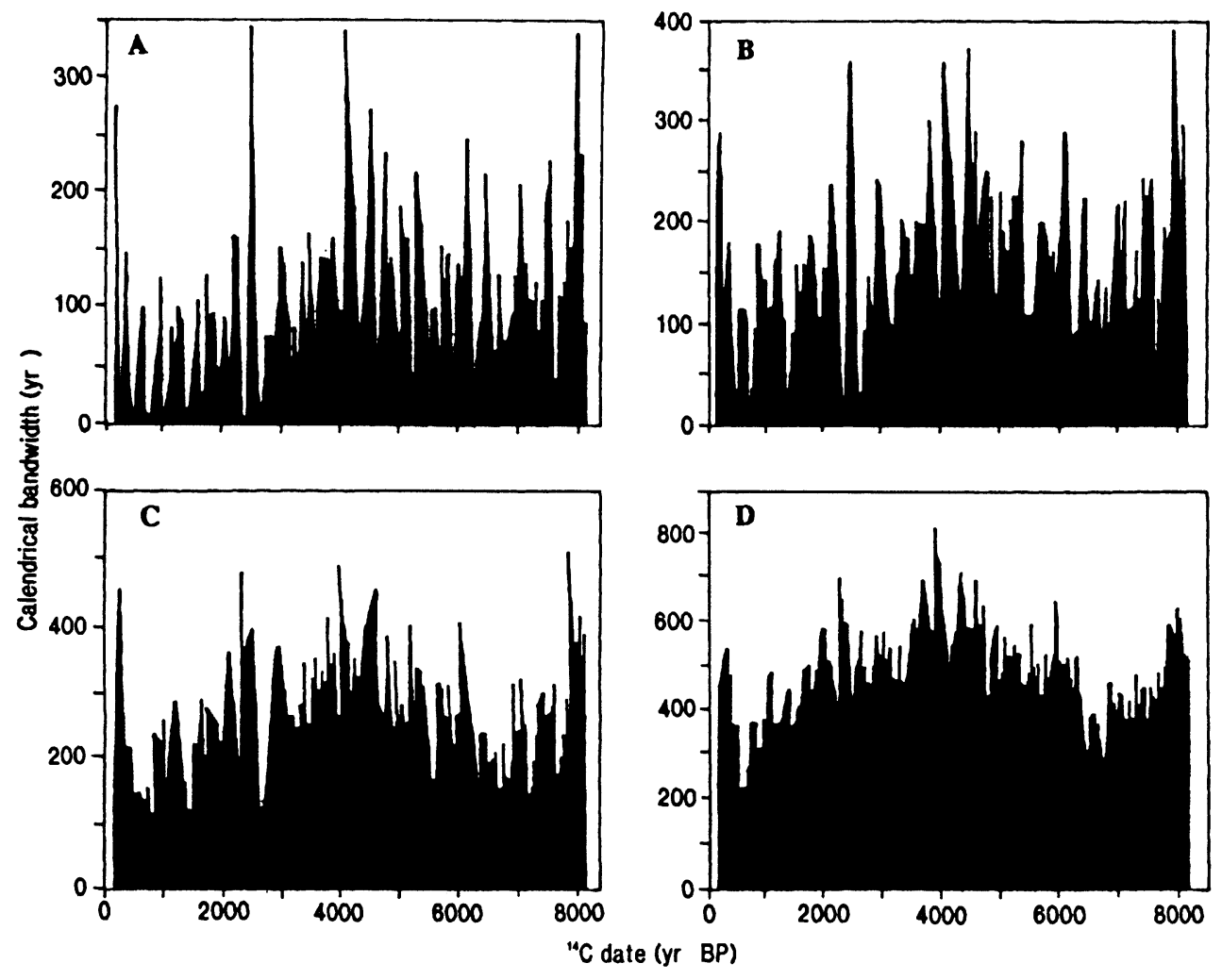

Fig. 2. Calendrical band widths in years as a function of ${ }^{14} \mathrm{C}$ age, in increments of $5 \mathrm{yr}$ from $8100-150$ BP. A. ${ }^{14} \mathrm{C}$ precision of $\pm 20 \mathrm{yr}$; B. ${ }^{14} \mathrm{C}$ precision of $\pm 50 \mathrm{yr}$; C. ${ }^{14} \mathrm{C}$ precision of $\pm 100 \mathrm{yr}$; D. ${ }^{14} \mathrm{C}$ precision of $\pm 200 \mathrm{yr}$

\section{RESULTS}

Figures 2(A-D) allow users of ${ }^{14} \mathrm{C}$ dates to ascertain what level of ${ }^{14} \mathrm{C}$ precision is required to obtain a given calendar band width at any time during the past nine millennia. The figures also show that even at the highest precisions (Fig. 2A), short intervals (e.g., 2400-2500 BP and 7900-8000 BP) exist when the advantages of high-precision dating are minimal. The period, 4000-5300 BP (i.e., the Neolithic to the beginning of the Bronze Age) gives the largest calendrical band widths. As the dating precision decreases from "high" to "routine" (i.e., $\pm 50 \mathrm{yr}$ ) the calendrical band widths widen (Fig. 2B), but the trends in band width remain similar, with the 4000-5300 BP period giving the largest uncertainties in calendar dates. The mean calendrical band widths for precisions of \pm 20 and $\pm 50 \mathrm{yr}$, found by averaging all band widths over $8100-150 \mathrm{BP}$, is $101 \mathrm{yr}$ and $158 \mathrm{yr}$, respectively.

Figure 2(C, D) shows that, as the dating precision decreases, the graphs representing calendrical band width as a function of ${ }^{14} \mathrm{C}$ precision take on a sinusoidal form, with an amplitude of $c a .250$ $\mathrm{yr}$ and a period of $12,000 \mathrm{yr}$ (assumed by extrapolation). The peak of the curve is at ca. $4000 \mathrm{BP}$ which is the point of greatest rate of change of $\Delta^{14} \mathrm{C}$ in the radiocarbon record (Fig. 3). Thus, as the precision decreases, the band width reflects more closely the rate of change of $\Delta^{14} \mathrm{C}$. To illustrate this graphically, we fitted a 4th-order Legendre polynomial to the $\Delta^{14} \mathrm{C}$ data derived from the ATM20 data set. We differentiated the resultant polynomial, plotted the calendrical band widths 


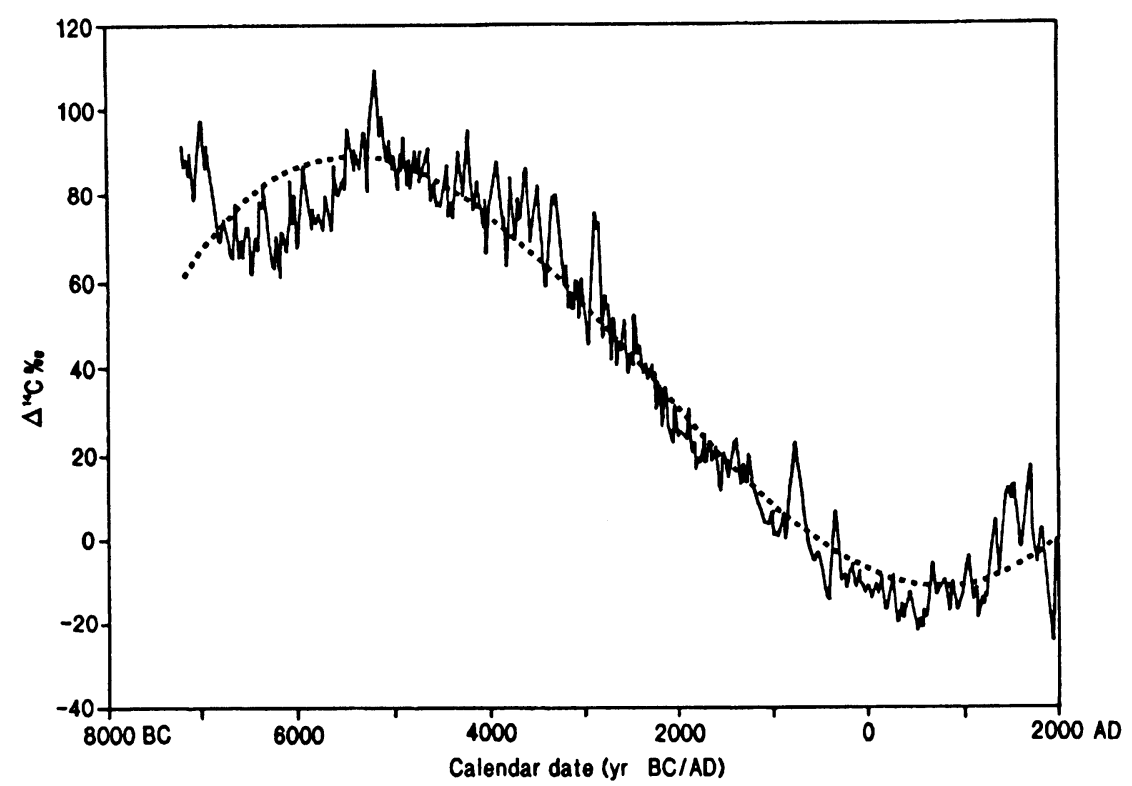

Fig. 3. $\Delta^{14} \mathrm{C}(\%)$ as a function of calendar year. Solid line is a 4 th-order polynomial fit to the data.

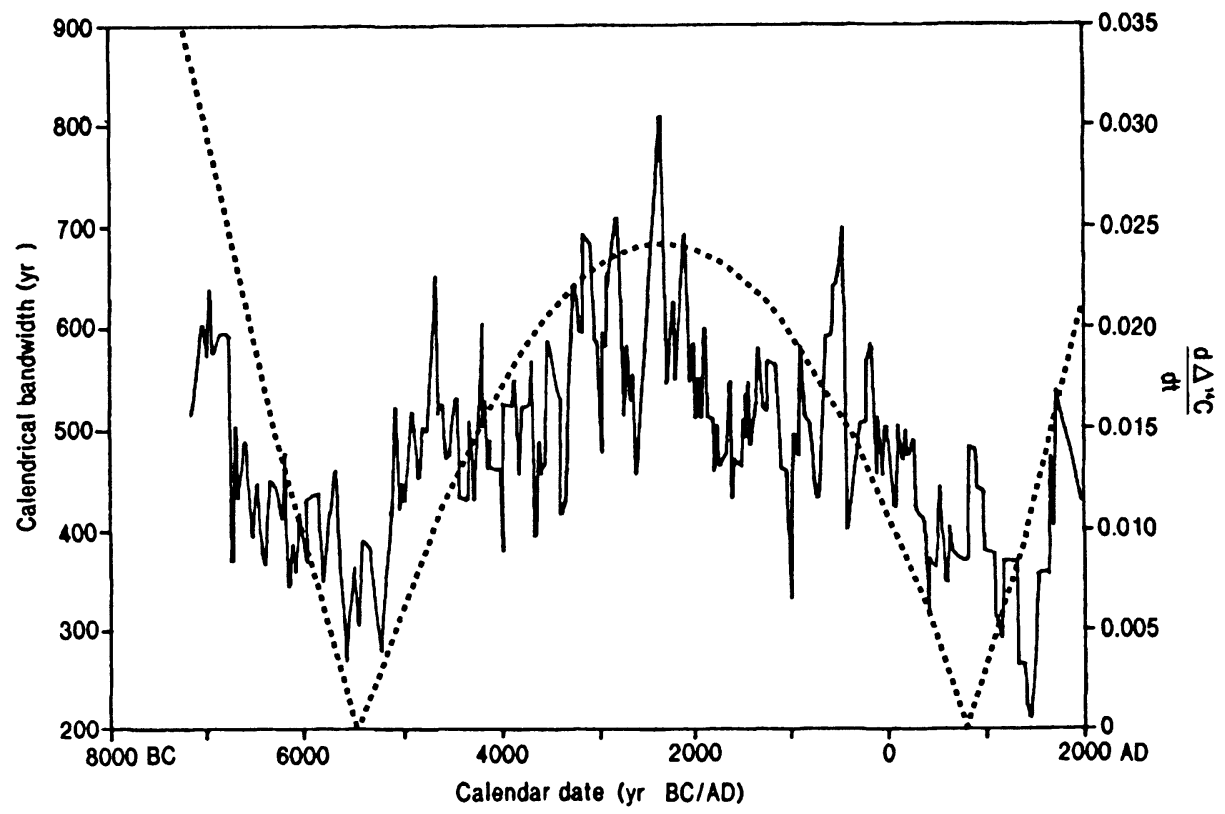

Fig. 4. Calendar band width as a function of calendar age for a ${ }^{14} \mathrm{C}$ precision of $\pm 200 \mathrm{yr}$ with the differentiated 4th-order polynomial shown in Figure 3 superimposed. This illustrates the good correspondence between the rate of change of $\Delta^{14} \mathrm{C}$ and calendrical band width at lower precisions. 


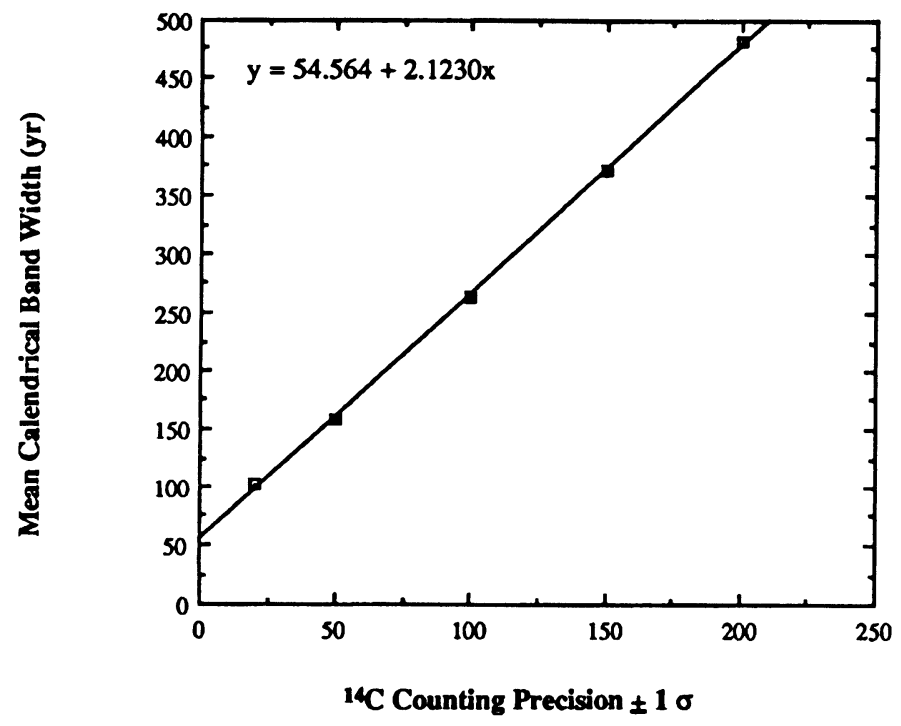

Fig. 5. Mean calendrical band width as a function of ${ }^{14} \mathrm{C}$ precision

as a function of calendar year, and superimposed the differentiated curve to show the good correspondence between peaks and troughs (Fig. 4). This illustrates that subtle changes in slope of the calibration curve are mimicked in the calendrical band widths at the lower precisions.

As the ${ }^{14} \mathrm{C}$ dating precision decreases, the calendrical band width increases. Figure 5 shows the mean calendrical band width over $7950{ }^{14} \mathrm{C}$ yr $v$ s. the ${ }^{14} \mathrm{C}$ precision of $\pm 20, \pm 50, \pm 100, \pm 150$ and $\pm 200 \mathrm{yr}$. A linear regression fit to these data gives

$$
\text { Mean band width }(\mathrm{yr})=2.12 \times{ }^{14} \mathrm{C} \text { precision }(1 \mathrm{\sigma})+54.56 \text {. }
$$

\section{CONCLUSIONS}

The band width of calendar dates $v s .{ }^{14} \mathrm{C}$ age (for dates with ${ }^{14} \mathrm{C} 1 \mathrm{\sigma}>100 \mathrm{yr}$ ) can be approximated by a sinusoid with an amplitude of $c a$. $250 \mathrm{yr}$ and a period of $c a .12,000 \mathrm{yr}$ with a peak at $4000 \mathrm{BP}$. For low-precision dates, this result illustrates the response of calibrated age range to long-term variations of atmospheric ${ }^{14} \mathrm{C}$, and specifically, to the long-term rate of change of $\Delta{ }^{14} \mathrm{C}$.

Although evidence for a similar cyclical variation exists in the band widths obtained at higher precisions (i.e., $1 \sigma<50 \mathrm{yr}$ ), the calendar age range is dominated by a series of isolated periods with very large band widths, even for precisions as low as $\pm 20 \mathrm{yr}$. These correspond to periods of rapid fluctuations or slow change in the atmospheric ${ }^{14} \mathrm{C}$ content.

A linear relationship exists between ${ }^{14} \mathrm{C}$ dating precision and the mean calendrical band width, found by averaging all band widths over $8100-150 \mathrm{BP}$

$$
\text { Band width }(\mathrm{yr})=2.12 \times{ }^{14} \mathrm{C} \text { precision }(1 \sigma)+54.6 \text {. }
$$

Thus, for high-precision dates (i.e., $\pm 20 \mathrm{yr}$ ), the calendar age range is typically $100 \mathrm{yr}$, whereas for routine dates ( $\pm 50 \mathrm{yr}$ ), a 160 -yr band width can be expected. Of course, these dates will be modulated by the variability noted above and can only be used as a guide. 


\section{ACKNOWLEDGMENTS}

F. G. McCormac would like to thank the Royal Society for a grant that helped initiate this study.

\section{REFERENCES}

Pearson, G. W. and Stuiver, M. 1986 High-precision calibration of the radiocarbon time scale, 500-2500 BC. In Stuiver, M. and Kra, R. S., eds., Proceedings of the 12th International ${ }^{14} \mathrm{C}$ Conference. Radiocarbon 28(2B): 839-862.

Stuiver, M. 1989 Dating proxy data. In Berger, A., Schneider, S. and Duplessy, J., eds., Climate and Geosciences. Dordrecht, The Netherlands, Kluwer Academic Publishers: 39-45.

Stuiver, M. and Becker, B. 1986 High-precision decadal calibration of the radiocarbon time scale, AD 19502500 BC. In Stuiver, M. and Kra, R. S., eds., Proceedings of the 12 th International ${ }^{14} \mathrm{C}$ Conference. Radiocarbon 28(2B): 863-910.

Stuiver, M. and Kra, R. S., eds. 1986 Calibration Issue. Proceedings of the 12th International ${ }^{14} \mathrm{C}$ Conference. Radiocarbon 28(2B): 805-1030.

Stuiver, M. and Pearson, G. W. 1986 High-precision calibration of the rad iocarbon time scale, AD 1950500 BC. In Stuiver, M. and Kra, R. S., eds., Proceedings of the 12 th International ${ }^{14} \mathrm{C}$ Conference. Radio- carbon 28(2B): 805-838.

Stuiver, M and Polach, H. A. 1977 Discussion: Reporting of ${ }^{14} \mathrm{C}$ data. Radiocarbon 19(3): 355-363.

Stuiver, M. and Reimer, P. J. 1986 A computer program for radiocarbon age calibration. In Stuiver, M. and $\mathrm{Kra}, \mathrm{R}$. S., eds., Proceedings of the 12th International ${ }^{14} \mathrm{C}$ Conference. Radiocarbon 28(2B): 1022-1030.

1987 User's guide to the programs CALIB and DISPLAY Rev. 2.1: Quaternary Isotope Laboratory, University of Washington.

Suess, H. E. and Linick, T. W. 1990 The ${ }^{14} \mathrm{C}$ record in bristlecone pine wood of the past 8000 years based on the dendrochronology of the late $\mathrm{C}$. W. Ferguson. In Proceedings of A Royal Society and Academie des Sciences Discussion Meeting. London, The Royal Society: 5-14.

Van der Plicht, J. and Mook, W. G. 1989 Calibration of radiocarbon ages by computer. In Long, A. and Kra, R. S., eds., Proceedings of the 13 th International ${ }^{14} \mathrm{C}$ Conference. Radiocarbon 31(3): 805-816. 